\title{
Evaluation of Saw Blade Designs on Controlling Dust from Cutting Fiber-cement
}

Aerosol and Air Quality Research

\section{OPEN ACCESS}

Received: February 4, 2021

Revised: April 13, 2021

Accepted: May 6, 2021

${ }^{*}$ Corresponding Author:

hif1@cdc.gov

\section{Publisher:}

Taiwan Association for Aerosol Research

ISSN: $1680-8584$ print

ISSN: 2071-1409 online

Copyright: U.S. Government work. This is an open access article distributed under the terms of the Creative Commons Attribution License (CC BY 4.0), which permits unrestricted use, distribution, and reproduction in any medium, provided the original author and source are cited.

\section{Chaolong Qi*, Seungkoo Kang}

Centers for Disease Control and Prevention, National Institute for Occupational Safety and Health, Division of Field Studies and Engineering, Cincinnati, $\mathrm{OH} 45226$, USA

\section{ABSTRACT}

Fiber-cement can contain as much as $50 \%$ crystalline silica and cutting this material has shown to cause excessive exposures to respirable crystalline silica. We conducted this study to evaluate different saw blades for cutting fiber-cement siding, aiming at identifying blade design features that lead to lower dust release. Through laboratory evaluations of 22 saw blades, the releasing rate of respirable dust, i.e., $\mathrm{G}_{\text {APS, }}$ was analyzed and compared with and without engineering control measures. Two on-tool passive control measures were specifically evaluated. First, a dust-collecting box with a capped exhaust port was attached to the circular saw. Second, the dust-collecting box was connected to a passive dust collector, which includes a cyclone dust collector and an air filter. Both control measures help collect a portion of the dust with the aid of the induced airflow from the fast-spinning blade. The $\mathrm{G}_{\text {APS }}$ generally increased with the number of teeth and the kerf width of the blades. However, the number of teeth seems to have a reduced effect on $\mathrm{G}_{\text {APS }}$ for the conditions with the two control measures, possibly due to a higher airflow rate induced by more blade teeth, which results in more dust captured by the dust collectors. The 4-tooth Hitachi blade had the lowest $\mathrm{G}_{\mathrm{APS}}$ under all three testing conditions, likely due to fewer teeth, thinner kerf, and its specific design characteristics of a "smooth" gullet optimizing induced airflow and dust transporting into the dust collectors. The control measure with the added passive dust collector provided a dust collection efficiency as high as $66 \%$. The gullet design of the blade seems to play an important role in affecting the amount of dust releasing as well as the collection efficiency of the passive dust controls.

Keywords: Respirable crystalline silica, Fiber-cement, Saw blade, Engineering control

\section{INTRODUCTION}

Respirable crystalline silica (RCS) refers to a portion of airborne particles containing crystalline silica with particle aerodynamic diameters less than approximately 10 micrometers $(\mu \mathrm{m})$, which is small enough to enter the gas-exchange regions of the lungs (NIOSH, 2002). Exposure to RCS is associated with silicosis. Greenberg et al. (2007) indicated that silicosis is irreversible and potentially fatal. Because no effective treatment exists for silicosis, prevention through exposure control is essential.

Cutting fiber-cement products can cause excessive exposure to RCS. According to Fairfax et al. (2004), uncontrolled exposure to RCS for workers using power saws to cut fiber-cement siding ranged from 0.02 to $0.27 \mathrm{mg} \mathrm{m}^{-3}$ during sampling, and their 8-hour time-weight-average (TWA) exposure ranged from 0.01 to $0.17 \mathrm{mg} \mathrm{m}^{-3}$ depending on the length of exposures on the day sampled. The highest exposure was 3.4 times the recommended exposure limit (REL) for RCS of $0.05 \mathrm{mg} \mathrm{m}^{-3}$ set by the National Institute for Occupational Safety and Health (NIOSH) in the United States. In an in-depth field survey, NIOSH (2013) reported that a cutter's uncontrolled exposures to RCS ranged from 0.06 to $0.13 \mathrm{mg} \mathrm{m}^{-3}$ when using power saws to cut fiber-cement siding, and the 8-hour TWA exposure ranged from $0.02 \mathrm{mg} \mathrm{m}^{-3}$ to $0.13 \mathrm{mg} \mathrm{m}^{-3}$. The highest result was 2.6 times the NIOSH REL for RCS. The findings from both field studies suggested that 
excessive exposures to RCS occurred when power saws were used without any engineering controls for cutting fiber-cement siding.

NIOSH (2014) characterized the dust generated from cutting fiber-cement siding using a variety of power tools under various operating conditions, and found that implementing local exhaust ventilation (LEV) by attaching a regular shop vacuum to a dust-collecting circular saw significantly reduced the dust releasing while cutting fiber-cement siding. The results from four field studies confirmed that the 95\% upper confidence limit for an 8-hour TWA exposure to RCS was only $30 \%$ of the NIOSH REL with the use of this simple and low-cost LEV control. Although the LEV control measure works effectively, it may not be desired under certain working conditions as the worker will need to drag a vacuum hose connected to the circular saw's exhaust port while frequently changing positions around the workbench. An engineering control measure without the use of an external vacuum may be preferred under such working conditions. In two of the four field surveys, NIOSH (2014) also evaluated a prototype circular saw with an on-tool dust collector. This tool had a dust-collecting feature with a built-in shroud covering the saw blade. The shroud connected to a cyclonic dust collector and a subsequent chamber which housed an air filter. When cutting fiber-cement siding, the fast-spinning blade induced an airflow, which carried a portion of the dust into the dust collector, thus eliminating the need for an external dust collector or shop vacuum. The geometric mean and the $95 \%$ upper confidence limit of the RCS exposure from six 8-hour TWA samples were $0.049 \mathrm{mg} \mathrm{m}^{-3}$ and $0.105 \mathrm{mg} \mathrm{m}^{-3}$, respectively. We hypothesize that the design of the blade may play an important role on inducing the airflow and collecting the dust during cutting. Therefore, improving the blade design may lead to higher induced flow and collection efficiency using similar on-tool dust collectors.

$\mathrm{NIOSH}$ (2014) also found that the dust generation rate from cutting fiber-cement siding was affected by the number of teeth on the saw blades and the rotating speed of the blades. Among 6 different saw blades tested (one $12.7 \mathrm{~cm}$ (5-inches), three $18.4 \mathrm{~cm}$ (7.25-inches), and two $30.5 \mathrm{~cm}$ (12-inches) diameter), the blades with more teeth generated considerably more dusts. Comparing $18.4 \mathrm{~cm}$ (7.25-inches) diameter blades, the generation rate of respirable dust using 28 carbide tipped teeth was 1.02 gram per meter $\left(\mathrm{g} \mathrm{m}^{-1}\right.$, gram of respirable dust generated with the cut of a linear-meter length of fiber-cement siding board, which has a thickness of $0.76 \mathrm{~cm}$ ), while it was $0.41 \mathrm{~g} \mathrm{~m}^{-1}$ with 4 Polycrystalline Diamond (PCD) tipped teeth. The generation rate also increased with the rotating speed of blades because more cutting interactions are expected with a faster rotating blade. Therefore, further improvements on saw blade designs may lead to lower RCS exposures by directly reducing the dust generation in addition to increasing induced flow and dust transportation into the dust collectors (either external ones or on-tool ones).

In this study, we evaluated and compared 22 different saw blades on their dust releasing rate in a laboratory setting with and without dust control measures. The term "dust releasing rate" is used instead of "dust generation rate" when control measures are applied as the generated dust can be either collected by the control measures or released. We then analyzed the results to identify saw blade designs with lower dust releasing rates and higher on-tool dust collection efficiencies, which is expected to lead to lower RCS exposure levels in practice for workers cutting fiber-cement siding.

\section{METHODS}

\subsection{Laboratory Testing System}

We conducted the laboratory characterization of dust from cutting fiber-cement siding in an automated laboratory testing system that has been used for a variety of airborne contaminant characterization experiments. Qi et al. (2016) used this system to characterize the silica dust generated by cutting fiber-cement siding, and Kang et al. $(2019,2020)$ recently used the same system to investigate the composition of emissions from sawing (2019) and sanding (2020) a solid surface composite material. A diagram of the laboratory testing system is shown in Fig. 1 . The locations of the sampling ports on the duct, the dimensions of the chamber and duct, and the operational flowrate were specifically designed to follow the European Standard EN 1093-3 (CEN 2006) for taking representative air samples to determine the releasing rate of the targeted airborne contaminants. 


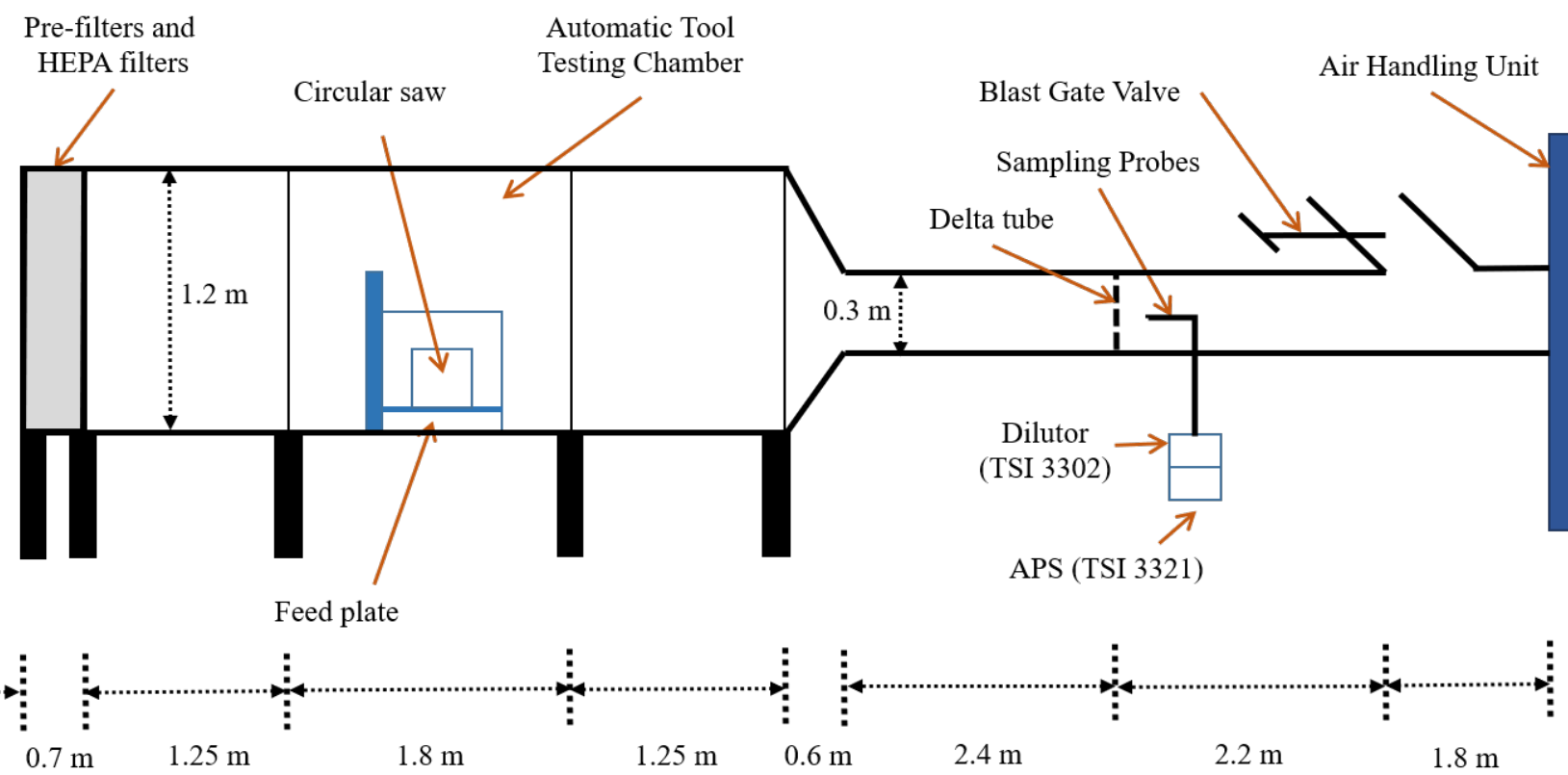

Fig. 1. Experimental setup of the Laboratory testing system.

Airflow was moved by an air handling unit (PSKB-1440, ProVent LLC, Harbor Springs, Michigan, USA) to carry dust particles that were released by cutting fiber-cement siding in an automatic tool testing chamber. The chamber featured controls using a Programmable Logic Controller (PLC) and a Human Machine Interface (HMI) so that automatic and repeatable cuts of a fiber-cement siding board can be achieved. The operation of a power tool was controlled using a two-dimensional actuator through the PLC, and the feed rate of a chain-driven feed plate to feed a siding board was controlled through the PLC. Board feed rate and power tool operation were programmed through the HMI. A dust-collecting circular saw (Model 5057KB, Makita U.S.A., Inc., St. La Mirada, California, USA) was mounted in the chamber and 22 saw blades were evaluated (See Supplementary Table S1, available in the supplementary material in the online edition). For each test, the flowrate of the testing system was set to $0.64 \mathrm{~m}^{3} \mathrm{~s}^{-1}$ by adjusting the blast gate valve, and the flowrate through the testing chamber was monitored by a micromanometer (PVM100 Airflow Developments Ltd., UK) connected to a delta tube (306AM-11-AO, Midwest Instrument, Sterling, Michigan, USA) on the duct. The flowrate used in this study was sufficient to allow the inhalable particles to remain airborne according to the EN 1093-3. To be consistent, the fiber-cement siding from James Hardie (Mission Viejo, California, USA) was used in all the tests. The tested fiber-cement siding boards have a width of $21.0 \mathrm{~cm}$ (8.25-inches), thickness of $0.76 \mathrm{~cm}$ (0.30-inches), and measured density of $1.27 \pm 0.01 \mathrm{~g} \mathrm{~cm}^{-3}$.

\subsection{Sampling Methods}

In this study, the automatic tool testing chamber was set to make a fixed number of repeat cuts of the fiber-cement siding board for each test condition. During each cut, a dust cloud was generated and carried downstream by the airflow through the chamber. For the measurement of airborne dust, an Aerodynamic Particle Spectrometer (APS, Model 3321, TSI Inc., Shoreview, Minnesota, USA) was applied to obtain a real-time size distribution of the dust in the aerodynamic size range of $0.5-20 \mu \mathrm{m}$, as illustrated in Fig. 2. The time resolution of the APS was 1 second, allowing it to capture the entire dust cloud profile for each individual cut and to avoid overlaps of measurements between two adjacent cuts. The APS continuously collected an aerosol stream from the duct sampling port at a 5 Liter per minute $\left(\mathrm{L} \mathrm{min}^{-1}\right)$ flowrate, and the measurements were repeated 5 times for each blade. An isokinetic sampling probe was designed for the APS with a matching flow velocity for the inlet of the sampling probe and the duct. The sampling probe was connected to an aerosol dilutor (model 3302A, TSI Inc, Shoreview, Minnesota, USA), which sat on the top of the APS. The dilutor provided a 100 to 1 dilution to minimize the measurement uncertainty that can be caused by high concentration aerosols. A size distribution of dust 


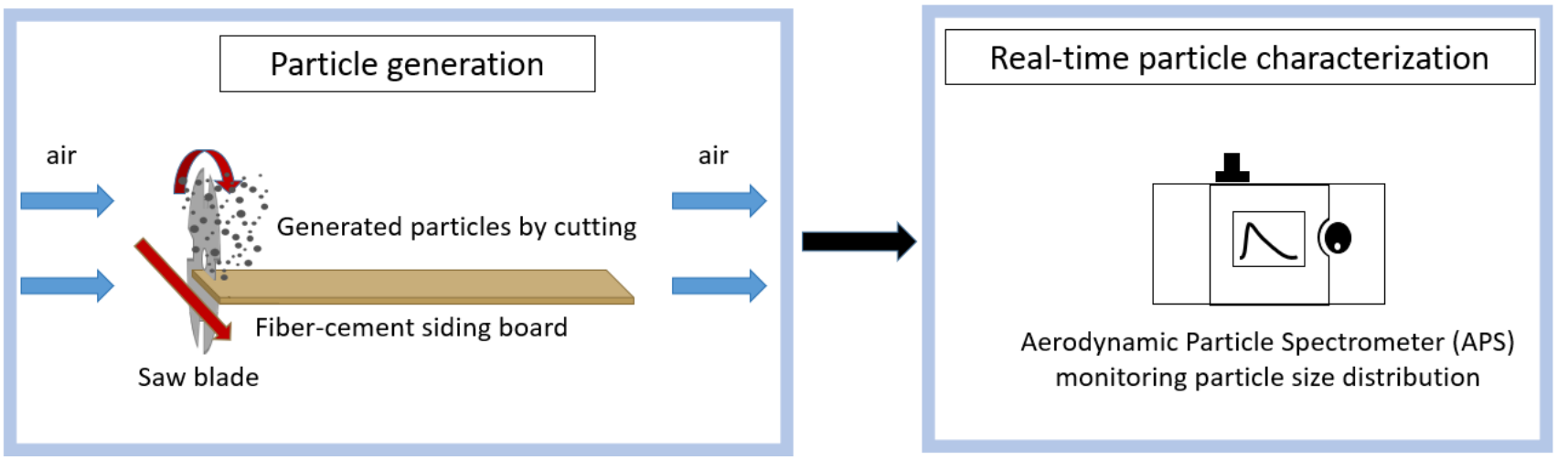

Fig. 2. Particle generation and real-time characterization.

measured by the APS is based on the number concentration, and the mass concentration of respirable dust was derived using the number concentration by the following equation:

$$
C_{m}=\sum_{i=1}^{52} \frac{\rho_{p} f_{i} \pi d_{e, i}{ }^{3} N_{i}}{6 \eta_{\text {dil. } i} \eta_{s p, i}}
$$

where, $C_{m}$ is the mass concentration of respirable dust, $d_{e, i}$ is the equivalent volume diameter of channel $\mathrm{i}$ in the APS that is calculated by $d_{e, i}=d_{a, i} \sqrt{\rho_{0} \chi / \rho_{p}}, d_{a, i}$ is the aerodynamic diameter of channel $i$ in the APS, $\rho_{0}$ is the unit density, $\rho_{\mathrm{p}}$ is the density of the dust, $\chi$ is the dynamic shape factor of the dust, $f_{i}$ is the respirable fraction of the dust with $d_{a, i}, N_{i}$ is the number concentration of the dust with $d_{a, i}, \eta_{\text {dil, }}$ is the transportation efficiency of the dust with $d_{a, i}$ through the diluter, and $\eta_{s p, i}$ is the transportation efficiency of the dust with $d_{a, i}$ through the sampling probe. The transportation efficiency of dust with $d_{a, i}$ through the diluter $\left(\eta_{\text {dil, }}\right)$ was provided by the diluter manufacturer and incorporated within the Aerosol Instrument Manager ${ }^{\circledR}$ Software (AIM V10.2, TSI Inc., Shoreview, Minnesota, USA). The transportation efficiency through the sampling probe $\left(\eta_{s p, i}\right)$, however, must be analyzed separately. The loss of dust inside the sampling probe can be attributed to the settling loss in the horizontal part of the probe, the inertial loss at the 90-degree bend, and the diffusion loss throughout the probe. These losses are size-dependent, so the overall loss of respirable dust depends on the size distribution of the dust generated during cutting. The overall loss of respirable dust was calculated using the equations summarized by Kulkarni et al. (2011) and the size distribution data from the APS, and it was found to be less than $1 \%$ combining all three aforementioned losses. Thus, $\eta_{\text {sp, } i}$ was assumed to be 1 in this study for simplicity.

The APS classifies the sampled dust size range into 52 channels with $d_{a, i}$ representing the aerodynamic diameter for each specific channel $i(i=1-52)$. In order to obtain the mass of dust in each channel, its density $\left(\rho_{p}\right)$ is needed, and its equivalent volume diameter needs to be calculated with the knowledge of its density and dynamic shape factor $(\chi)$. In this study, all the dust generated from cutting fiber-cement siding was assumed to be spherical, thus a dynamic shape factor of 1 was applied. In reality, the dust particles are not perfect spheres. However, the average $\chi$ among different tests are not expected to change due to the use of the same type and batch of fiber-cement siding boards. Thus, the use of a consistent $\chi$ allows an unbiased comparison among different tests. The dust density was also needed for the Stokes correction of the APS data because the APS was factory calibrated using Polystyrene Latex (PSL) spheres with a density close to $1.05 \mathrm{~g} \mathrm{~cm}^{-3}$. However, obtaining the dust density is not straightforward because the bulk material in fiber-cement siding is a mixture of a few different ingredients and the density might vary depending on the size of the dust. Therefore, the measured board density was used as the dust density in this study. With the assumed dynamic shape factor and density for the sampled dust, the mass concentration of respirable dust derived from the APS data and Eq. (1) could be different from the actual value. However, this difference should be consistent among all the APS data and should not affect the comparison of the releasing rate of respirable dust derived from the APS data under different testing conditions. In this study, the releasing rate of respirable dust ( $\left.\mathrm{G}_{\mathrm{APS}}\right)$ is defined by Eq. (2): 


$$
G_{A P S}=\frac{\sum_{t=1}^{T_{s}}\left(C_{m, t} Q\right)}{W}
$$

where, $C_{m, t}$ is the mass concentration of respirable dust at time $t, Q$ is the volume flowrate in the testing system, $0.64 \mathrm{~m}^{3} \mathrm{~s}^{-1}, \mathrm{~T}_{\mathrm{s}}$ is the total sampling time of the APS for one cut, and W is the board width.

The APS data contains one set of dust size distribution for every second during the test, which leads to a $C_{m, t}$ data point for each second using Eq. (1). Thus, the summation of $C_{m, t} Q$ during the sampling time $T_{s}$ results in the total mass of respirable dust released for one cut. The releasing rate of respirable dust defined in Eq. (2) represents the mass of respirable dust generated per unit linear length cut.

\subsection{Procedure for a Cutting Test}

The automatic tool testing system was programmed to perform a pre-determined number of cuts. Each cut included the following steps: 1) the feed plate fed the board;2) power was supplied to the tool; 3) the 2D actuator moved the tool and made a cut; 4) the tool was turned off; and 5) the $2 \mathrm{D}$ actuator moved the tool back to its original position. A waiting time of about 5 seconds was programmed between steps 2) and 3) to ensure the blades of the power saw reached the designed rotating speed before making a cut. The sliding speed for the saw was set to be $2.54 \mathrm{~cm} \mathrm{~s}^{-1}$ by the PLC.

\subsection{Test Conditions}

The Makita 5057KB circular saw was used to test 22 saw blades listed in Supplementary Table S1. This saw has an option to attach a dust-collecting box as shown in Fig. 3. In this study, we tested each saw blade with the three conditions listed below:

A. Without control (naked blade).

B. Capped dust-collecting box (exhaust port capped).

C. Dust-collecting box plus a passive dust collector (a cyclone and a filter cartridge).

The dust-collecting box installed on the circular saw served as a receiving hood, so the airflow induced by the fast-spinning blade helps transport a portion of the generated dust into the box, thus reducing the overall dust releasing rate. The exhaust port of the box can be either capped or connected to a dust collector. A capped exhaust port (test condition B) may restrict the induced

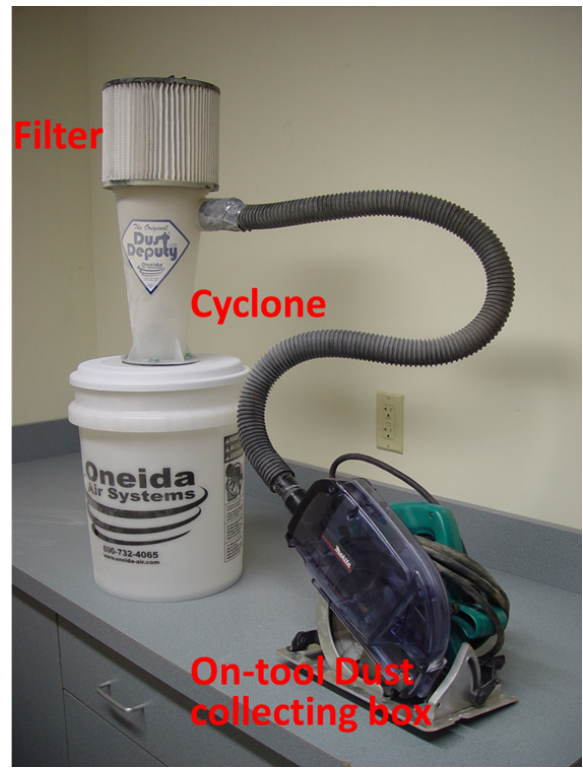

Fig. 3. A circular saw (Makita 5057KB) with an on-tool dust-collecting box for test condition B, and a passive dust collector (a cyclone and a filter cartridge) for test condition $\mathrm{C}$. 
flow. Test condition $\mathrm{C}$ simulated the operation of an on-tool dust collector with a passive dust collector assembled by using a cyclone (model AXD000004, Oneida Air Systems, Inc., Syracuse, New York, USA) and a filter cartridge (part number 90304, Shop-Vac ${ }^{\circledR}$ Corporation, Williamsport, Pennsylvania, USA) mounted on the cyclone's outlet. Aided by the induced flow, larger particles are collected by the dust-collecting box and the cyclone, and the smaller particles are collected by the filter cartridge. We hypothesized that different saw blade designs regarding their shape and number of teeth may induce different amounts of airflow, leading to different levels of dust releasing rates under test conditions $B$ and $C$. The effect of the blade characteristics on induced airflow may be especially important for test condition $C$ as the induced airflow is expected to be higher than that of test condition B, which has the induced airflow blocked by the cap. Therefore, a collection efficiency $(\eta)$ is defined in Eq. (3) to serve as an indicator of how well the induced flow from different blade designs enhance collecting dust particles into the dust-collecting box and passive dust collector, eventually reducing $\mathrm{G}_{\text {APS }}$.

$$
\eta=1-\frac{G_{A P S, \text { test condition } C}}{G_{A P S, \text { test condition A }}}
$$

If the outlet of the dust-collecting box is connected to an active dust collector such as a shop vacuum, the airflow provided by the shop vacuum will substantially overpower the induced flow by the blade, thus the dust releasing rates can be much lower for all evaluated saw blades. Therefore, using a shop vacuum may not be ideal for the evaluation of blade design. Consequently, we only tested the shop vacuum for comparison purposes solely with a Diablo saw blade (\#1 in Table 1). For this comparison test, a 12-gallon shop vacuum (model 586-62-11, Shop-Vac ${ }^{\circledR}$ Corporation, Williamsport, Pennsylvania, USA) was used as the active dust collector. Fig. 4 shows the circular saw and its connection to the shop vacuum, which came with a disposable filter bag (part number 90662, Shop-Vac ${ }^{\circledR}$ Corporation, Williamsport, Pennsylvania, USA) to trap most of

Table 1. Respirable dust releasing rate $\left(\mathrm{G}_{\mathrm{APS}}, \mathrm{g} \mathrm{m}^{-1}\right)$ from the cutting test for different saw blades.

\begin{tabular}{|c|c|c|c|c|c|c|c|}
\hline & \multirow[b]{2}{*}{ Brand } & \multirow[b]{2}{*}{$\begin{array}{l}\text { Number of } \\
\text { teeth }\end{array}$} & \multirow[b]{2}{*}{$\begin{array}{l}\text { Kerf width } \\
(\mathrm{cm})\end{array}$} & \multicolumn{3}{|c|}{ Respirable dust releasing rate $\left(\mathrm{G}_{\mathrm{APS}}, \mathrm{g} \mathrm{m}^{-1}\right)$} & \multirow{2}{*}{$\begin{array}{l}\text { Collection } \\
\text { efficiency } \\
(\%)\end{array}$} \\
\hline & & & & $\begin{array}{l}\text { A: Without } \\
\text { control }\end{array}$ & $\begin{array}{l}\text { B: Capped dust } \\
\text { collecting box }\end{array}$ & $\begin{array}{l}\text { C: Dust collecting box }+ \\
\text { a passive dust collector }\end{array}$ & \\
\hline 1 & Diablo & 4 & 0.180 & 0.33 & 0.26 & 0.19 & $41 \%$ \\
\hline 2 & Gila & 4 & 0.221 & 0.43 & 0.37 & 0.25 & $43 \%$ \\
\hline 3 & Gila & 6 & 0.221 & 0.43 & 0.37 & 0.24 & $45 \%$ \\
\hline 4 & Gila & 8 & 0.221 & 0.46 & 0.40 & 0.22 & $53 \%$ \\
\hline 5 & Malco & 4 & 0.231 & 0.38 & 0.33 & 0.22 & $42 \%$ \\
\hline 6 & Oldham & 4 & $0.234^{*}$ & 0.35 & 0.30 & 0.16 & $55 \%$ \\
\hline 7 & Board Pro & 5 & 0.231 & 0.37 & 0.36 & 0.25 & $32 \%$ \\
\hline 8 & Timberline & 4 & 0.180 & 0.36 & 0.26 & 0.17 & $53 \%$ \\
\hline 9 & CMT & 4 & 0.170 & 0.36 & 0.28 & 0.18 & $50 \%$ \\
\hline 10 & DeWalt & 6 & 0.229 & 0.45 & 0.34 & 0.18 & $60 \%$ \\
\hline 11 & Grip-Rite & 4 & 0.221 & 0.38 & 0.30 & 0.20 & $47 \%$ \\
\hline 12 & Hitachi & 4 & 0.180 & 0.29 & 0.22 & 0.12 & $60 \%$ \\
\hline 13 & Hitachi & 8 & 0.221 & 0.50 & 0.37 & 0.21 & $58 \%$ \\
\hline 14 & Marathon & 4 & 0.180 & 0.44 & 0.35 & 0.22 & $51 \%$ \\
\hline 15 & Ivy classic & 4 & 0.180 & 0.35 & 0.28 & 0.18 & $48 \%$ \\
\hline 16 & Makita & 4 & 0.221 & 0.33 & 0.30 & 0.20 & $39 \%$ \\
\hline 17 & Plank Kutter & continuous & DNA & 1.07 & 0.88 & 0.57 & $47 \%$ \\
\hline 18 & Original & 4 & $0.226 *$ & 0.25 & 0.27 & 0.19 & $26 \%$ \\
\hline 19 & Oshlun & 4 & 0.221 & 0.45 & 0.36 & 0.22 & $52 \%$ \\
\hline 20 & PacTool & 4 & 0.221 & 0.38 & 0.27 & 0.14 & $63 \%$ \\
\hline 21 & TASK & 4 & 0.221 & 0.47 & 0.32 & 0.16 & $66 \%$ \\
\hline 22 & $\mathrm{BOSCH}$ & 4 & 0.259 & 0.41 & 0.37 & 0.29 & $29 \%$ \\
\hline
\end{tabular}

Note: DNA - Does Not Apply; * - Not specified by the manufacturer and measured manually. 


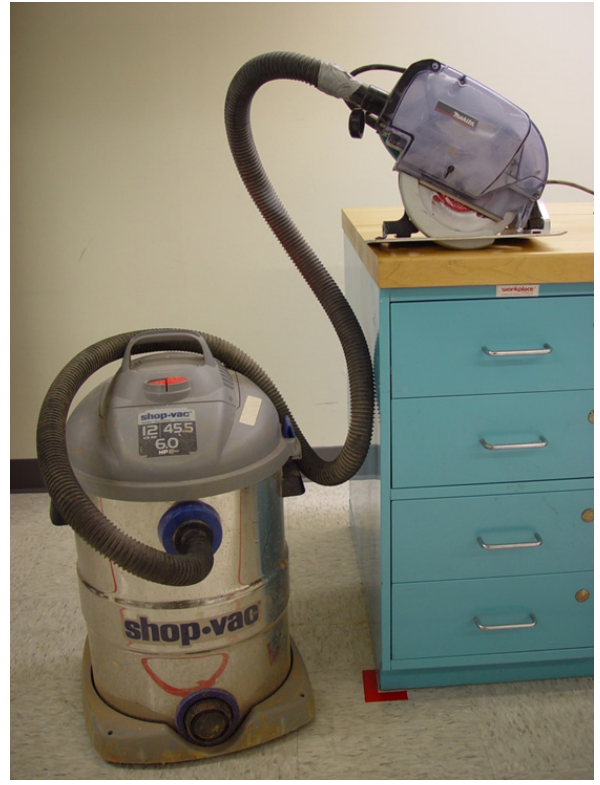

Fig. 4. The dust-collecting circular saw and its connection to the shop vacuum.

the dust, and a standard Prolong cartridge filter (part number 90304, Shop-Vac ${ }^{\circledR}$ Corporation, Williamsport, Pennsylvania, USA) to capture the dust passing through the filter bag. The shop vacuum was rated to provide a $5.66 \mathrm{~m}^{3} \mathrm{~min}^{-1}$ (200 CFM) flowrate by the manufacturer. However, the actual flowrate can be affected when the shop vacuum is connected to the filters and vacuum hose. More importantly, the flowrate might change due to dust loading on the filter bag and cartridge filter. A laboratory test found that the flowrate of this shop vacuum was generally in the range of $1.95-2.96 \mathrm{~m}^{3} \mathrm{~min}^{-1}$ (69-105 CFM).

\section{RESULTS}

\subsection{Size Distribution of Dust with Control Measures}

Fig. 5 shows the number-based size distributions of the dust released from cutting fibercement siding using a Diablo saw blade (\#1 in Table 1) with three different engineering control measures. Each data point is the averaged result of five replicates, and the error bars represent the standard deviations of the corresponding data points. The small error bars associated with most data points verify the high repeatability of these tests.

The size distributions showed a lognormal distribution with a geometric mean diameter ranging from 0.9-1.1 $\mu \mathrm{m}$ and a geometric standard deviation ranging from 1.5-1.9. The total number concentration, however, varied considerably among different tests, meaning that the dust removal efficiency was much affected by the engineering control measures. As expected, the largest amount of dust was released without engineering control applied (test condition A) with an average total number concentration of 10,026 particles $\mathrm{cm}^{-3}$ that was estimated from fitting the data to a lognormal distribution. Compared to the test condition A, both the test condition $B$ (capped dust-collecting box) and $C$ (dust-collecting box plus a passive dust collector) considerably reduced the dust releasing. The average total number concentrations for condition $B$ and $C$ are 7,040 and 5,003 particles $\mathrm{cm}^{-3}$, which are about $30 \%$ and $50 \%$ lower than that of the condition $\mathrm{A}$. The reduced particle concentration observed was achieved by the airflow induced by the blade moving a portion of dust into the box and the passive dust collector. The test condition $B$ removes dust less effectively due to the restricted airflow with a capped exhaust port. The test with the shop vacuum connected to the exhaust port of the dust-collecting box (Fig. 4) resulted in the least amount of dust, 497 particles $\mathrm{cm}^{-3}$, which corresponds to a $\sim 95 \%$ reduction of total particle numbers compared to the test condition A. The low particle concentration observed when using the shop vacuum is expected as the much higher airflow is provided by the shop vacuum, and this result is consistent with the finding from the previous study by NIOSH (2014) using the Hitachi PCD 


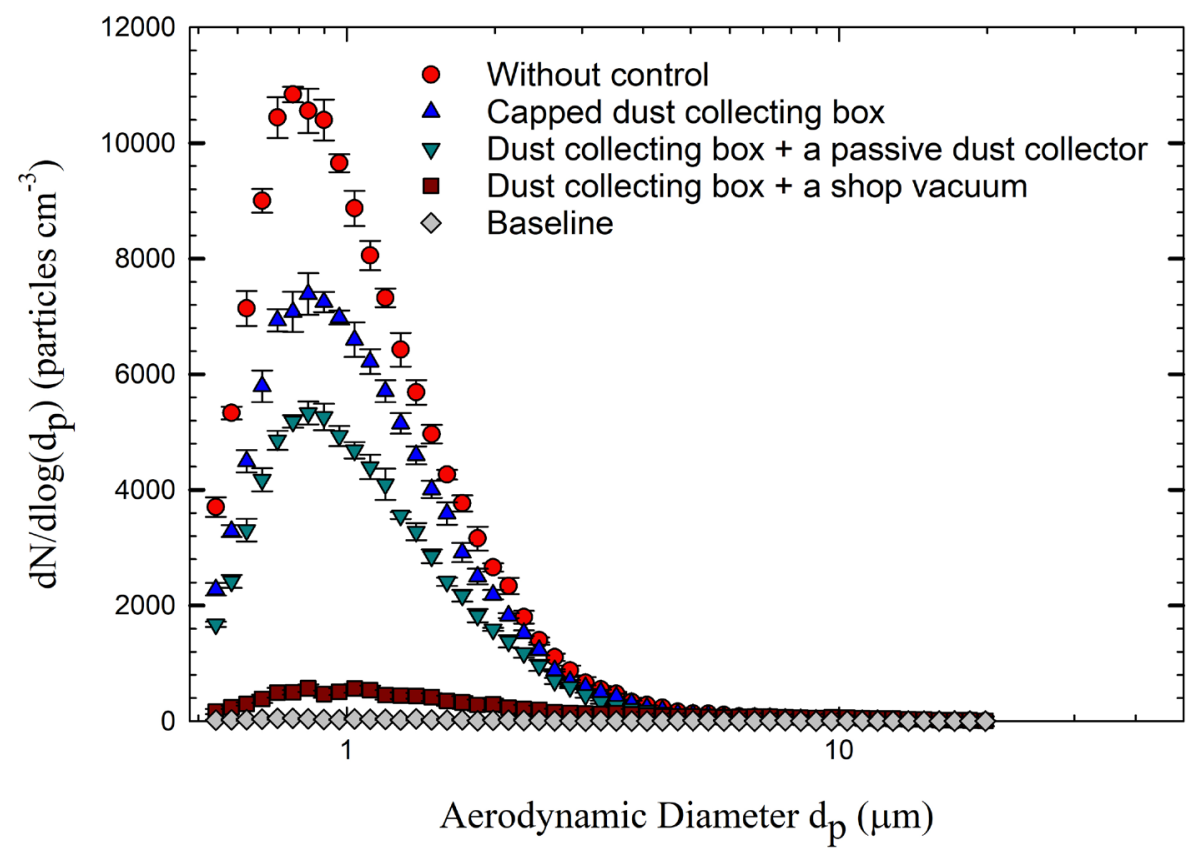

Fig. 5. Number-based size distributions of the dust from cutting a fiber-cement siding obtained from the APS.

blade (Model 18008, Hitachi Power Tools, Valencia, CA; \#12 in Table 1) on the same circular saw. Please note that the concentration levels shown in Fig. 5 are those monitored in the laboratory setting, which can be very different from those experienced in actual work practice, although the shape of the size distribution is expected to be similar. Furthermore, the number concentrations for particles larger than approximately $3 \mu \mathrm{m}$ are not apparent in Fig. 5 due to their low concentration levels. However, these larger particles were adequately monitored by the APS and their contributions to the dust releasing rate, $\mathrm{G}_{\mathrm{APS}}$, was captured as defined in Eq. (2). The massbased size distribution is expected to have a similar shape to what was reported previously by NIOSH (2014) using the same testing method, which has a bimodal lognormal distribution with a larger mode around $13 \mu \mathrm{m}$, and another mode smaller than $5 \mu \mathrm{m}$.

Table 1 lists the dust releasing rate, $\mathrm{G}_{A P S}$, for the 22 different blades computed based on Eq. (2), and each result is the average from 5 replicates. The average relative standard deviation (RSD, the ratio of the standard deviation to the average) for all the $\mathrm{G}_{\text {APS }}$ was only $3.3 \%$, indicating the excellent repeatability of the test; therefore, the standard deviation for each $\mathrm{G}_{\text {APS }}$ is not reported here. As shown in the table, the $\mathrm{G}_{\mathrm{APS}}$ varied depending on the blade models with no engineering control measure applied (test condition A), ranging from $0.25-1.07 \mathrm{~g} \mathrm{~m}^{-1}$. The highest $\mathrm{G}_{\text {APS, }}$ $1.07 \mathrm{~g} \mathrm{~m}^{-1}$, was found from the Plank Kutter ${ }^{\circledR}$ blade (\#17 in Table 1), which has a continuous rim of diamond tips. The blades with more teeth interact with the fiber-cement board more often per rotation, thus the Plank Kutter ${ }^{\circledR}$ blade is expected to generate the largest amount of dust. Excluding the Plank Kutter ${ }^{\circledR}$ blade, the range of $\mathrm{G}_{\text {APs }}$ for the test condition $A$ is $0.25-0.50 \mathrm{~g} \mathrm{~m}^{-1}$.

In general, the $\mathrm{G}_{A P S}$ decreased when control measures were applied. With the capped dustcollecting box attached to the circular saw (test condition $B$ ), the range of $\mathrm{G}_{\text {APS }}$ was reduced to $0.22-0.40 \mathrm{~g} \mathrm{~m}^{-1}$ (excluding the Plank Kutter ${ }^{\circledR}$ blade). As expected, it was further reduced to $0.12-$ $0.29 \mathrm{~g} \mathrm{~m}^{-1}$ when the passive dust collector was connected to the dust-collecting box (test condition $\mathrm{C}$ ).

The $\mathrm{G}_{\text {APS }}$ for the Diablo blade (\#1 in Table 1) used with the shop vacuum test is $0.06 \pm 0.03 \mathrm{~g} \mathrm{~m}^{-1}$. The relative larger RSD for this particular test is due to larger counting uncertainty in the APS with much lower particle counts as most particles are collected. In comparison, the average $\mathrm{G}_{\text {APS }}$ for the 4-tooth Hitachi blade (\#12 in Table 1) used in the same saw and shop vacuum was reported at $0.03 \mathrm{~g} \mathrm{~m}^{-1}$ from the study conducted by NIOSH (2014). The lower $\mathrm{G}_{\text {APs }}$ for the 4-tooth Hitachi blade compared to the Diablo blade is consistent with the results shown in Table 1.

As expected from the hypothesis mentioned earlier, GAPS varied considerably with blade 
models among all the three test conditions. The performance of the two passive control measures seems to depend on the characteristics of blades such as their shape and number of teeth as they may affect the induced airflow rate. As shown in Table 1, the collection efficiency varies with the blade models ranging from $26 \%$ to $66 \%$.

\subsection{Effect of Blade Design on Respirable Dust Releasing Rate}

The average $G_{\text {APS }}$ with different kerf widths is summarized in Table 2. Please note that only the blades with 4 teeth are included for this comparison so that the effect from the number of teeth does not interfere. The $\mathrm{G}_{\text {APS }}$ vary greatly depending on the blade design, making it difficult to assess the sole effect of kerf width on $\mathrm{G}_{\text {APS. }}$. Therefore, we categorized the blades into two groups with one group having kerf width smaller than $0.220 \mathrm{~cm}(0.085$-inch) and another group with larger kerf width. The results reported in the table clearly show that the average $\mathrm{G}_{\text {APS }}$ decreased (about 10\%) with smaller kerf width for all the three test conditions due to smaller contact area. However, the difference for test condition $A$ and $C$ is not statistically significant ( $P$ value $\geq 0.1$ ).

The effect of the number of teeth on $\mathrm{G}_{\text {APS }}$ was investigated and listed in Table 3 . The blades were categorized into three groups that have 4, 6 and 8 teeth, for all three testing conditions. As expected, blades having more teeth result in higher $\mathrm{G}_{\text {APS }}$ in general because of more cutting interactions between the blade teeth and the fiber-cement board. However, this effect seems to be reduced for the conditions with the passive dust controls. There were only two data points for each of the two groups with 6 and 8 teeth, so we performed a statistics analysis by combing these two groups and comparing with the group with 4 teeth. The effect of the number of teeth on $\mathrm{G}_{\text {APS }}$ is statistically significant for test conditions $A$ and $B(P<0.010)$; and it is not statistically different for test condition $C(P=0.13)$. A plausible explanation for the diminished effect when using the passive dust collector is that although more teeth on the blade generated more dust, they also induced a higher airflow rate, which result in more dust being transported into the dustcollecting box and the passive dust collector. This is also evidenced by the higher collection efficiency with the larger number of teeth. In fact, when further examining the three Gila blades, which have 4,6 , and 8 teeth and the same other blade characteristics, the GAPs decreased with the number of teeth when the passive dust collector was used.

\section{DISCUSSION}

The data listed in Table 1 shows that the lowest $\mathrm{G}_{\text {APS }}$ was reported from the 4-teeth Hitachi blade (\#12) under the two test conditions with passive controls. Fewer teeth, thinner kerf, and its specific design characteristics may contribute to its lowest dust releasing rate. This blade also shows one of the highest collection efficiencies at $60 \%$, indicating that its design help induce

Table 2. Average respirable dust releasing rate $\left(\mathrm{G}_{\mathrm{APS}}, \mathrm{g} \mathrm{m}^{-1}\right)$ from the fiber-cement saw blades having a kerf width smaller or larger than $0.220 \mathrm{~cm}(0.085$-inches).

\begin{tabular}{llll}
\hline & \multicolumn{2}{c}{ Respirable dust releasing rate $\left(\mathrm{G}_{\left.\mathrm{APS}, \mathrm{g} \mathrm{m} \mathrm{m}^{-1}\right)}\right.$} \\
\cline { 2 - 4 } Kerf with $(\mathrm{cm})$ & A: Without control & B: Capped dust collecting box & $\begin{array}{l}\text { C: Dust collecting box }+ \\
\text { a passive dust collector }\end{array}$ \\
\hline smaller than .220 & 0.35 & 0.28 & 0.18 \\
larger than .220 & 0.38 & 0.32 & 0.20 \\
$P$ value & 0.16 & 0.03 & 0.10 \\
\hline
\end{tabular}

Table 3. Average respirable dust releasing rate $\left(\mathrm{G}_{\mathrm{APS}}, \mathrm{g} \mathrm{m}^{-1}\right)$ from the fiber-cement saw blades having different number of teeth.

\begin{tabular}{lllll}
\hline \multirow{2}{*}{$\begin{array}{l}\text { Number } \\
\text { of tooth }\end{array}$} & A: Without control & B: Capped dust collecting box & $\begin{array}{l}\text { C: Dust collecting box }+ \\
\text { a passive dust collector }\end{array}$ & $\begin{array}{l}\text { Collection } \\
\text { efficiency } \\
(\%)\end{array}$ \\
\cline { 2 - 5 } & & 0.30 & 0.19 & $48 \%$ \\
6 & 0.37 & 0.36 & 0.21 & $53 \%$ \\
8 & 0.44 & 0.38 & 0.22 & $55 \%$ \\
\hline
\end{tabular}


(a) Board Pro (\#7)

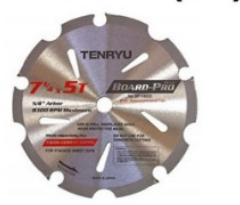

(b)

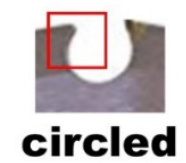

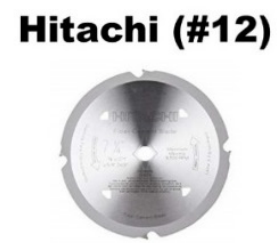

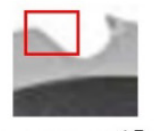

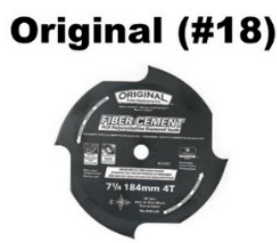

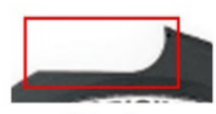

flat
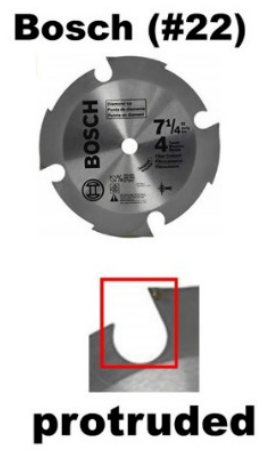

Fig. 6. Pictures of (a) saw blades (\#7, \#12, \#18, and \#22 from the left) and (b) Enlarged tooth pictures for comparison.

airflow and transport dust into the subsequent dust collectors. More specifically, it has a semicircular gullet with the non-tooth side having a smoother curve leading to the blade's rim, which seems to be on the same circumference as the other side of the gullet (Fig. 6). Such a "smooth" gullet may be at an optimized balance between inducing airflow and transporting the dust into the dust collectors. This hypothesis is evidenced by the relatively high collection efficiency for the blades with a similar "smooth" gullet design (\#9, \#10, \#11, \#13, \#14, \#19, \#20, \#21 in Supplementary Table S1 and Table 1).

Fig. 6 illustrates the gullet design for three other blades, which have the lowest collection efficiency. The Board Pro blade (\#7) has a gullet that is almost a $3 / 4$ circle. It is apparent that such a "circled" design is not ideal for inducing airflow due to its enclosing feature. The Original blade (\#18) has a gullet that is "flat" on its non-tooth side. Since the gullet is less enclosed, it may induce more airflow. However, it may be too open to keep the generated dust in the induced flow, resulting in lower collection efficiency and less dust removal. The Bosch blade (\#22) has its PCD tip protruding considerably beyond the rim of the other side of the gullet. With such a design, generated dust may easily disperse in all directions without being captured by the induced airflow. Overall, the lower collection efficiencies for these three blades may attribute to their gullet designs.

The test results clearly show that the blade design affects the dust generation as well as the dust collection by the passive dust control measures. The uncapped dust-collecting box does not lead to satisfactory dust collection. However, after adding the passive dust collector, it results in considerably higher dust collection, with a collection efficiency as high as $66 \%$. In theory, the collection efficiency could translate into a similar amount of exposure reduction compared to the uncontrolled exposure.

The average $\mathrm{G}_{\text {APS }}$ for the Diablo blade used with the passive dust collector $\left(0.19 \mathrm{~g} \mathrm{~m}^{-1}\right)$ is 3.2 times higher than the average $G_{A P S}$ when it was used with the shop vacuum $\left(0.06 \mathrm{~g} \mathrm{~m}^{-1}\right)$. Since the passive dust collector is to simulate the operation of the power saw that had an on-tool dustcollecting feature, we compared the data from the two field surveys by NIOSH (2014) when the same Diablo blades were used with both the Makita circular saw with shop vacuum and the power saw with on-tool dust collector. The average 8-hour TWA exposure when using the ontool dust collector $\left(0.060 \pm 0.039 \mathrm{mg} \mathrm{m}^{-3}\right.$ from 6 samples) was 4.0 times higher than that for the Makita saw with shop vacuum $\left(0.015 \pm 0.012 \mathrm{mg} \mathrm{m}^{-3}\right.$ from 9 samples). The results suggest that the comparison of the average $G_{\text {APS }}$ found from the laboratory evaluation for the two control measures (dust-collecting box plus passive dust collector versus shop vacuum) is in reasonably good agreement with that of their corresponding average 8-hour TWA exposures obtained from the field surveys.

The 4-tooth Hitachi blade (\#12 in Table 1) exhibited the lowest GAPS when using the passive dust collector $\left(0.12 \mathrm{~g} \mathrm{~m}^{-1}\right)$, which is $63 \%$ of the average $\mathrm{G}_{\text {APS }}$ for the diablo blade under the same testing condition $\left(0.19 \mathrm{~g} \mathrm{~m}^{-1}\right)$. Additional blade design improvements with optimized gullet may be considered for higher induced airflow and better dust transportation into the dust collector. With an improved blade design, it is possible to further reduce the 8-hour TWA exposure from the level found from the on-tool dust control with the Diablo blade $\left(0.060 \pm 0.039 \mathrm{mg} \mathrm{m}^{-3}\right)$, thus 
possibly meeting the NIOSH REL $\left(0.05 \mathrm{mg} \mathrm{m}^{-3}\right)$. Such an engineering control measure, once validated from field surveys, may be an alternative to the one using a shop vacuum. Although it may be difficult to reduce the exposure to the same level as the control of using a shop vacuum, the control of using an on-tool passive dust collector would provide the benefit of avoiding carrying an additional shop vacuum and its hose during the work.

\section{CONCLUSION}

The blade tests revealed that the dust releasing rate, $\mathrm{G}_{\mathrm{APS}}$, generally increases with the number of teeth and the kerf width of the blades. The effect of the number of teeth was greatly reduced when the passive dust control measures were used, possibly because more teeth may induce a higher airflow although they generate more dust. The passive dust control measures of using a capped dust-collecting box and the box with a passive dust collector both led to considerable amounts of dust collection. The control measure with the passive dust collector provided a dust collection efficiency as high as $66 \%$ depending on the blade design. The 4-tooth Hitachi blade (\#12 in Table 1) resulted in the lowest dust releasing rate with the two passive dust control measures. The gullet design of this blade seems to play an important role in affecting the amount of dust generation as well as the collection efficiency of the passive dust controls. Further improvement of the blade design is promising to lead to RCS exposure below the NIOSH REL while cutting fiber-cement siding using similar on-tool passive dust control measures.

\section{DISCLAIMER}

The findings and conclusions in this report are those of the authors and do not necessarily represent the official position of the National Institute for Occupational Safety and Health, Centers for Disease Control and Prevention. Mention of any company or product does not constitute endorsement by the National Institute for Occupational Safety and Health, Centers for Disease Control and Prevention.

\section{SUPPLEMENTARY MATERIAL}

Supplementary material for this article can be found in the online version at https://doi. org/10.4209/aaqr.210028

\section{REFERENCES}

European Committee for Standardization (CEN) (2006). Safety of machinery - Evaluation of the emission of airborne hazardous substances - Part 3: Test bench method for measurement of the emission rate for a given pollutant. EN 1093-3. CEN, Brussels, Belgium.

Fairfax, R., Lofgren, D.J., Johnson, D.C., Walley, T.L. (2004). OSHA Compliance Issues. J. Occup. Environ. Hyg. 1, D1-D6. https://doi.org/10.1080/15459620490264418

Greenberg, M.I., Waksman, J., Curtis, J. (2007). Silicosis: A review. Dis. Mon. 53, 394-416. https://doi.org/10.1016/j.disamonth.2007.09.020

Kang, S., Liang, H., Qian, Y., Qi, C. (2019). The composition of emissions from sawing Corian ${ }^{\circledR}$, a solid surface composite material. Ann. Work Expo. Health 63, 480-483. https://doi.org/10.109 3/annweh/wxz009

Kang, S., Liang, H., Qian, Y., Qi, C. (2021). The composition of emissions from sanding Corian ${ }^{\circledR}$ with different sandpapers. Aerosol Air Qual. Res. 21, 200377. https://doi.org/10.4209/aaqr.20 20.07.0377

Kulkarni, P., Baron, P.A., Willeke, K. (2011). Aerosol measurement: Principles, techniques, and applications. John Wiley \& Sons, New York.

National Institute for Occupational Safety and Health (NIOSH) (2002). NIOSH hazard review: Health effects of occupational exposure to respirable crystalline silica. Cincinnati, OH: U.S. Department of Health and Human Services, Public Health Service, Centers for Disease Control 
and Prevention, National Institute for Occupational Safety and Health, DHHS (NIOSH) Publication No. 2002-129.

National Institute for Occupational Safety and Health (NIOSH) (2013). Partnering to control dust from fiber-cement siding. Qi, C., Echt, A., See, M. Cincinnati, OH: U.S. Department of Health and Human Services, Public Health Service, Centers for Disease Control and Prevention, National Institute for Occupational Safety and Health EPHB Report No. 358-11a. https://www. cdc.gov/niosh/surveyreports/pdfs/358-11a.pdf

National Institute for Occupational Safety and Health (NIOSH) (2014). Evaluation of the dust generation and engineering control for cutting fiber-cement siding. By Qi, C., Echt, A., Gressel, M., Feng, A. Cincinnati, OH: U.S. Department of Health and Human Services, Centers for Disease Control and Prevention, National Institute for Occupational Safety and Health, EPHB Report No. 358-16a. https://www.cdc.gov/niosh/surveyreports/pdfs/358-16a.pdf

Qi, C., Echt, A., Gressel, M.G. (2016). On the characterization of the generation rate and sizedependent crystalline silica content of the dust from cutting fiber cement siding. Ann. Occup. Hyg. 60, 220-230. https://doi.org/10.1093/annhyg/mev066 